\title{
TOPOMETRY FEM OPTIMIZATION OF THE WING STRUCTURE OF THE TRANSPORT AIRCRAFT
}

\author{
Tomáš KATRŇÁK ${ }^{1}$, Jaroslav JURAČKA ${ }^{2}$ \\ Institute of Aerospace Engineering, Faculty of Mechanical Engineering, Brno University of Technology, \\ Technická 2896/2, Brno 61669, Czech Republic \\ E-mails: ${ }^{1}$ katrnak@fme.vutbr.cz (corresponding author); \\ ${ }^{2}$ juracka@fme.vutbr.cz
}

Received 01 October 2014; accepted 04 May 2016

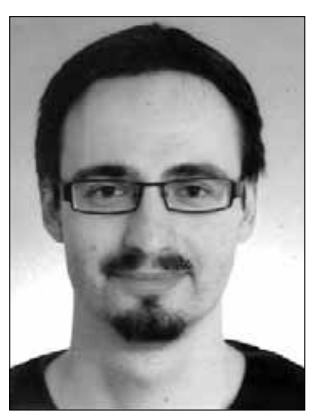

Tomáš KATRŇÁK, Eng.

Education: Brno University of Technology, Czech republic.

Affiliations and functions: since 2007, researcher at Brno University of Technology, Faculty of

Mechanical Engineering, Institute of Aerospace Engineering.

Research interests: load capacity of aircraft structures, structural optimization.

Publications: author of 3 articles and 4 conference papers.

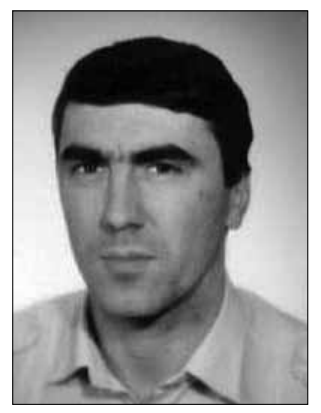

Jaroslav JURAČKA, Assoc. Prof. Eng, PhD

Education: Brno University of Technology, Czech republic.

Affiliations and functions: since 2012, Director of the Institute of Aerospace Engineering of

FME BUT; 2000-2006, Head of the Aircraft test laboratory, at the Institute of Aerospace

Engineering of BUT.

Non-University activities: member of the Czech Society for Mechanics at the Academy of

Science of the Czech Republic; member of the Czech Aeronautical Amateur Association,

helicopter and gyrocopter group.

Research interests: airframe structures and testing, composite structures, fatigue.

Publications: author of 14 scientific articles and 18 conference papers.

Other activities: leader of the grant of 7FP EU no. 264084, CEDESA - "Centre of Excellence for the Design of Efficient and Safe Aircraft"; co-leader of the EU grants FP6, FP7: KhAI-ERA, CESAR, CELPACT; participation on development of L410 NG, VUT 100 Cobra,

EV-55 Outback, four gliders and several ultralight aircraft.

\begin{abstract}
The article presents the topometry optimization of the critical semi-shell wing structure of the aircraft in the Commuter category of the CS-23 regulation standard (EASA 2012). Modern finite element (FE) optimization methods are used. The main outcome is that the milled integral lower wing panel allows significant weight savings due to an optimization of the thickness of each skin segment. The FE model validation with the analytical software and the selection of structural constraints and requirements for the optimization are described in this article. Also, a final stress analysis and a complex load capacity analysis validate required properties of designed structural modifications with an optimal stress distribution. Additionally the analysis of weight savings and elongation of the fatigue durability according to the Damage tolerance methodology was done.
\end{abstract}

Keywords: FEM, topometry optimization, wing structure, stress analysis.

\section{Introduction}

In this paper, the methods, conditions and requirements for the practical optimization of a semi-shell wing structure are presented. This analysis was made on demand by the aircraft producer, and the main purpose was to obtain the optimal structural design and to select the locations for weight savings in the wing structure of the L 410 NG aircraft in the Commuter category of the 
CS-23 regulation standard from EASA (2012), which is currently being designed in the MOSTA project. The semi-shell wing structure was designed with the use of analytical methods in the first stage. Then the modern finite element optimization methods implemented in the MSC.Nastran software could design an optimal stress distribution. The structural optimization is the process of such a design which fulfils all requirements and simultaneously minimizes weight or other efficiency decreasing factors. The utilized methods are based on the state-of-the art methods, see Qiu et al. (2014) and Li et al. (2014). An introduction to this problem was presented in student's diploma thesis (Jurek 2013) and the part of the analysis in Katrňák and Juračka (2015). This article describes the optimization of entire wing structure, updated results and the analysis of weight savings and elongation of the fatigue durability according to the Damage tolerance methodology. This work is a proper example of the collaboration among the aircraft producer, student and the university.

\section{Aircraft structure}

The L 410 NG aircraft is a new generation of previous successful types of L 410 aircraft produced in Aircraft Industries, a.s. One of these types is illustrated in Figure 1. The Institute of Aerospace Engineering also participates in the design of the L 410 NG aircraft, which is a metal-structure twin-engine commuter category aircraft with the capacity of 19 passengers. The aircraft's modernization allows for a higher maximum take-off weight, higher payload and more efficient operation characteristics. The Damage tolerance philosophy is utilized in this design to increase the aircraft fatigue durability. The semi-shell wing structure was designed using analytical methods in the first stage. Therefore, there was an opportunity to improve the design with finite element methods (FEM) employed to find the optimum design with a lower weight. The modern FE optimization solution sequences implemented in the MSC.Nastran software were used. The main outcome was that the milled integral lower wing panel allowed significant weight savings due to an optimization of the thickness of each

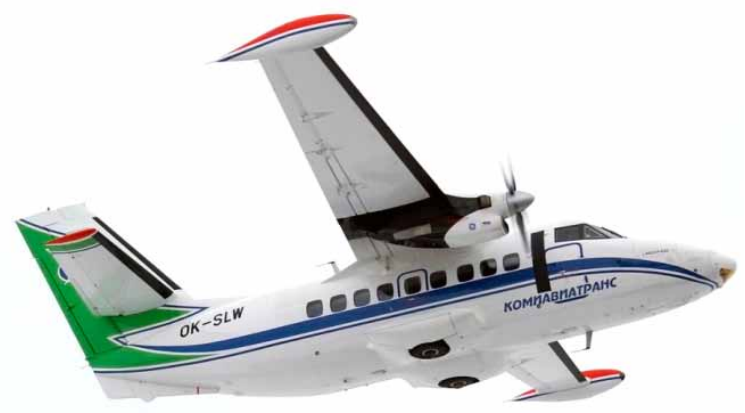

Fig. 1. View of the lower wing panel on the previous type of commuter category aircraft L 410

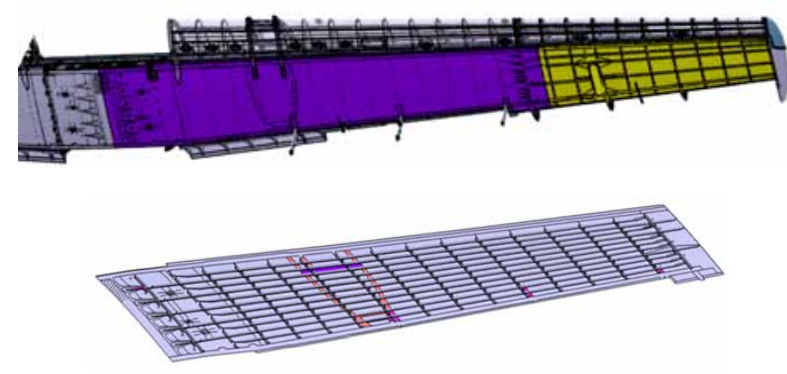

Fig. 2. Detail of the initially designed milled lower wing panel

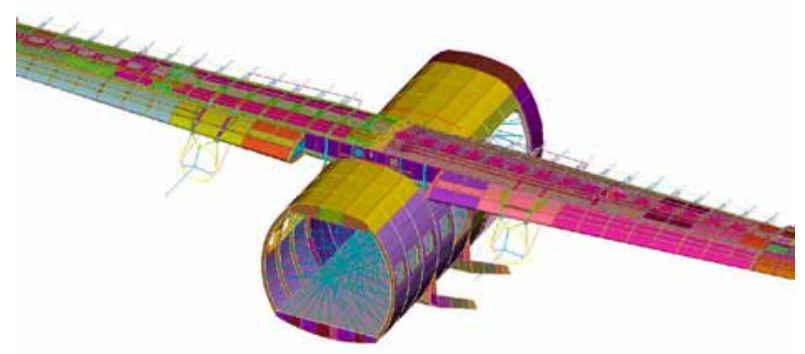

Fig. 3. The analyzed FE model of the wing structure attached to the central aircraft fuselage part

skin or stringer segment. This part is shown in Figure 2. The FE model for the computation is presented in Figure 3. All the aerodynamic, engine and inertial forces were assumed and the most critical wing load cases were selected. The special load cases according to the fatigue requirements were added. Then the maximum allowed values for normal stress were determined as the stress limits for the optimization process.

\section{The FE model of the wing structure and applied load}

The FE model used in the structural analysis consisted of the wing and the middle part of the fuselage. Because rigid attachments in the wing joints could influence stress distribution and the analysis, the fuselage part was added to the arrangement. This assembly was meshed with 285661 CQUAD4 shell elements and 6779 CTRIA3 elements. For the connections of the specific components or for load application the bar, beam, rod elements and the RBE connectors were used. The structural analysis was computed in the MSC.MD Nastran 2010.1 software with the FE solution sequence "Sol 200".

A detail of the optimized model section of the semishell wing structure is shown in Figure 4. The integral lower wing panel with stiffening stringers is illustrated there.

The entire wing and fuselage assembly was attached to the main undercarriage spars in the lower part of the fuselage. These were the displacement restrictions in boundary conditions. A group of the most critical load 


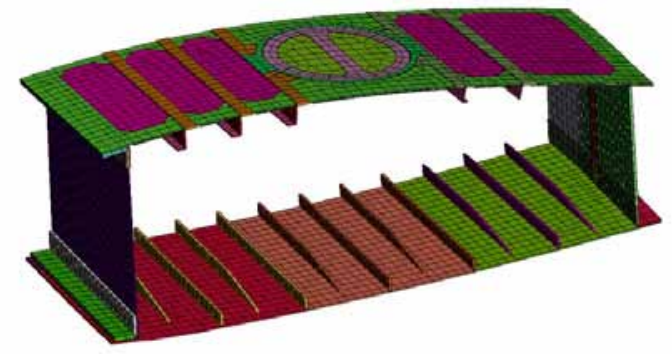

Fig. 4. Detail of the FE model of the designed semi-shell wing structure

cases was selected from the combinations of the aircraft flight envelope cases and the mass configurations. The flight envelopes include the maneuvering, gust, aileron and flap conditions. The load was applied to predefined structural sections to substitute a proper aircraft load during flight.

\section{Validation of FE analysis with analytical software}

The results of the FE linear static analysis were compared with the results from the analytical software, which is named the Stauno software (Jurek 2013). The wing section structure and the applied load were identical for both. The main purpose was to derive the difference and accuracy of the FE method used. The values of the skin and stringer normal stresses were compared in the selected sections for the load case LC30. According to the comparison with analytical results, the accuracy of the FE analysis was determined. The normal stress difference was about $4 \mathrm{MPa}$, which equals to a $7 \%$ difference. Thus, the created FE model was validated and could be used for the following optimization.

\section{Optimization}

Structural optimization is the process of a design which fulfils all the strength, stiffness and fatigue requirements and minimizes the weight or other efficiency decreasing factors. Weight is the objective function of the optimization. The structural shape and dimensions create the design space. The general classification of optimization methods could be made according to the character of unknown variables:

- parametrical optimization;

- functional optimization.

The location of the objective function's extreme is sought in the parametrical optimization. The second one is the functional optimization, which selects the function with an extreme value. The following classification is more complex:

- deterministic (gradient, nongradient);

- stochastic (evolution algorithms).

For our purposes the deterministic method of the extreme gradient was selected.

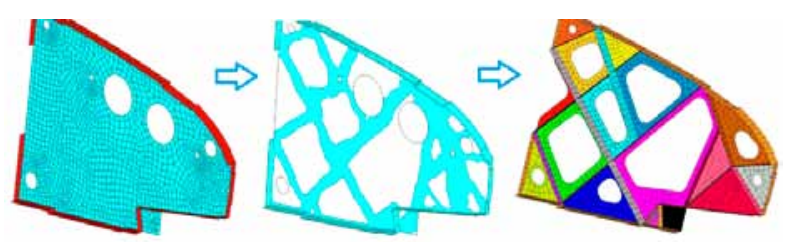

Fig. 5. An example of a topology optimized wing rib structure of an Airbus A380 aircraft
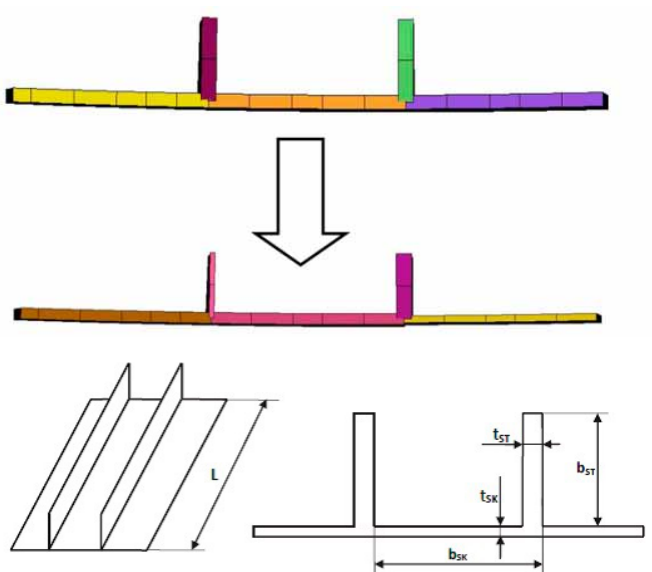

Fig. 6. An example of the thickness optimization of panel skins and stringers

The main types of the structural optimization are the topology and topometry optimizations. The topology optimization assesses if a material is needed at the location or not. Afterwards, finite elements are added or deleted. An example of a topology optimized wing rib is depicted in Figure 5 from Altair HyperWorks (2012).

If the structural shape, distances and the number of stiffeners must be kept, the topometry optimization is the required solution, as only the thicknesses of the elements are varied. Such an example is presented in Figure 6, where the initial material distribution on the integral lower wing panel is optimized for the given boundary conditions. The thicknesses of the panel skins and stringers are modified to the maximal material utilization.

A proper optimal design is one which reaches the minimum of the objective function and fulfils all requirements. An example of possible designs is presented in Figure 7. The optimal design must not exceed stress limits. This first type of design is declined, because it is unsafe and could cause a stability problem. The second design has reserves from limits, but it is inefficient due to the improper utilization of the structural rigidity. The optimal design reaches the stress limit and fulfills all other required conditions.

\section{FE solution sequence}

For optimization the solution sequence "Sol 200" was used, which enables the shape optimization or topometry optimization of structural member shapes. This 


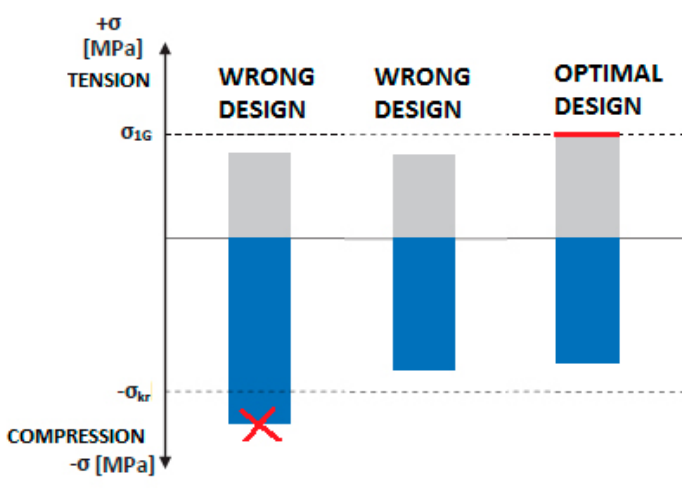

Fig. 7. A comparison of unsafe, inefficient and optimal designs

powerful tool is included in the MSC.Nastran software as a complete set of solutions for optimization. Detail description is in MacNeal-Schwedler Corporation (2008 and 1992). This optimization tool could be utilized for stress, mass or fatigue optimization with varying design variables in an allowed design space. Our design task combines all mentioned requirements, starting from the optimization at a predefined point with initial structural dimensions. The solution sequence "Sol 200" utilizes linear analysis "Sol 101" in each iteration to obtain the current stress distribution in a modified FE model.

\section{Selection of limits and requirements}

The design parameters of the optimization were the thicknesses of shell elements in the FE model. The heights and distances between the stringers were constant. Only the thicknesses of stringer and skin elements could vary. This created many possible combinations. Therefore, this large design space was restricted according to the technological and fatigue requirements. The upper thickness limit of $\mathrm{t}=6 \mathrm{~mm}$ was selected according to the Damage tolerance philosophy, because the crack propagation is faster in the higher thickness of a material. This upper limit was applied to the whole FE model of the lower wing panel.

The lower thickness limit was derived from the technological and regulation requirements. The regulation CS 23.954 in EASA (2012) describes the protection of the fuel system against lightning strikes. A detailed analysis according to this regulation divided the wing structure with the integral fuel tank into specific lightning zones. Therefore, along the integral fuel tank, the minimal thicknesses were restricted to $t=0.6 \mathrm{~mm}$ and the thicknesses of $\mathrm{t}=2 \mathrm{~mm}$ were required on the outer wing sections.

The upper stress limit for the load in tension was derived from fatigue analyses. The defined fatigue durability of the entire aircraft was 30000 flight hours; therefore, the tensile stress limit was set to Sigmalg =
52.5 $\mathrm{MPa}$ in the regular zone (without cutout or stress concentrations). The lower normal stress limit was determined from the stability, load capacity or strength requirements. The initial structure of the lower wing panel was designed as an integral panel consisting of a panel skin and small stiffening flanges marked as stringers. The example of the integral panel is presented in Figure 6. For this integral type of the stiffened panel the sizing and design requirements and methods from Niu (1999) were used. Also, other methods, mainly used only for stringers and described in Megson (2007) and Čtverák et al. (1997), were utilized to conform to the determined compression limits. The stability problems of the panel or particular structural elements (skin regions, stringer segments) limited the lower compression level.

The objective function was the weight of the lower wing panel. During the minimization of this basic function the determination of the gradient step in each iteration was controlled by convergence criterions. These criterions were essential parameters of the optimization. The criterion of the absolute difference of the objective function compared the current and previous objective function values:

$$
\operatorname{CONV} 2=F(x)^{k}-F(x)^{k-1}=1 \cdot 10^{-20} .
$$

The criterion of the relative difference of the objective function:

$$
\text { CONV } 1=\frac{F(x)^{k}-F(x)^{k-1}}{F(x)^{k-1}}=0.001 .
$$

These conditions controlled the step length on the gradient in a design space.

\section{Results of optimization analysis}

Significant possibilities in material and weight savings were enabled in the lower wing integral panel. From the initial design based on analytical methods the solution sequence "Sol 200" modified the element thicknesses and the mass distribution to an optimal design of the wing structure. The differences between the initial and optimized design are shown in Figure 8 with the colouring of stress distributions in the lower wing panel. In the upper part of the Figure 8 the initially designed panel with an improperly utilized material and structural rigidity is illustrated. The low stressed regions are marked in green colours. The optimized design has more regions with red colours, which correspond to the higher stress and higher utilization of the material distribution. This final optimal design presents the lowest possible panel weight and fulfills all requirements and limitations. Afterwards, the final load capacity analysis of the selected wing sections was made and confirmed the proper design of the structure.

The significant weight savings of about $7.6 \%$ were reached on the entire wing structure. In the first wing 

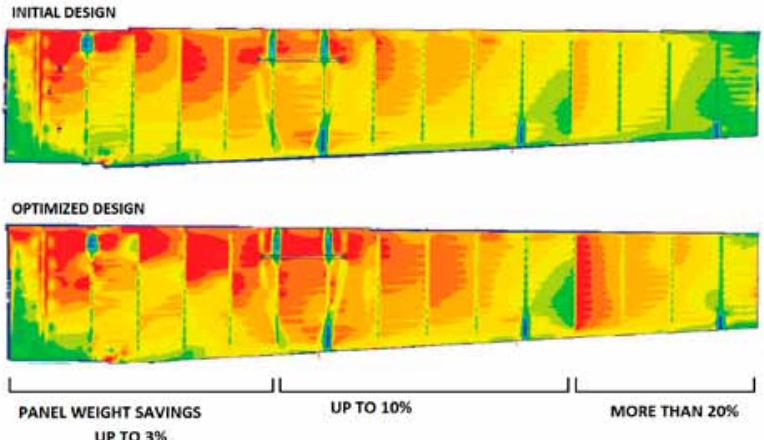

Fig. 8. A comparison of the stress distribution in the initial and optimized designs

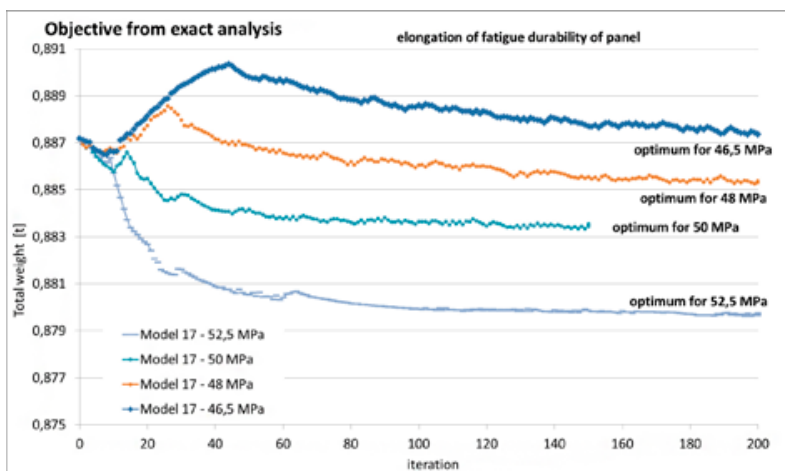

Fig. 9. A comparison of the optima of the objective function for various stress limits

region from a wing root there are weight savings of up to $3 \%$, as marked in Figure 8 . The second wing region allows savings of up to $10 \%$, and the last wing region shows the highest weight savings by more than $20 \%$ in a comparison with the initial analytical design. The last wing region close to the wing tip is out of the critical lightning zone and, therefore, has a lower thickness limit. The position of the integral fuel tank and regulation requirements from EASA (2012) related to the lightning protection mainly influenced the stress distribution in the wing panel structure.

\section{Elongation of the fatigue durability}

The history of the objective function from the exact analysis during iteration process is illustrated in Figure 9. Each optimum was validated by a set of optimization computations with various convergence criterions in inputs. This process confirmed the stable convergence to the optimum design level with the same value of objective function and similar element thicknesses. The first optimization was done for the tensile stress limit Sigmalg = 52.5 MPa, which corresponds to the required fatigue durability of 30000 flight hours. Following optimizations were done for stress limit modifications with the purpose to elongate the fatigue durability. The graphic comparison is illustrated in Figure 9. The decreasing stress limit as the essential optimization constraint increases the weight of the structure, but significantly affects the fatigue durability according to the Damage tolerance methodology. A required value of the objective function was reached for the stress limit Sigmalg = 46.5 MPa. This optimal design has the weight of the assembly identical to the initial weight, but estimated fatigue durability is elongated to the level of about 33000 flight hours. This increased value is very important for the planning of service inspections and the aircraft competitiveness on the market.

\section{Conclusions}

This article describes the topometry optimization of a critical semi-shell wing structure of the aircraft in the CS-23 Commuter category. This very complex FE model of the wing assembly was optimized only by varying the panel skin and stringer thicknesses. Modern FE optimization methods implemented in the MSC.Nastran software designed the optimal material distribution in the lower wing panel structure with the lowest possible panel weight and fulfilled all strength, stiffness, stability and fatigue requirements of the L $410 \mathrm{NG}$ aircraft.

The preliminary optimization with general constraints, according to only structural and material requirements indicated significant weight savings of about $46 \%$. But in the detailed design with employment of the certification requirements, practical aircraft operation, production costs and technological demands, the structural weight savings of about $7.6 \%$ were reached. This detailed design is mainly affected by the position of the integral fuel tank and regulation requirements from EASA (2012) related to the lightning protection. The analysis of elongation of the fatigue durability according to the Damage tolerance methodology was done as well.

\section{Acknowledgements}

These outcomes were supported by the project TE02000032 - Advanced Aerostructures Research Centre. This project was realized with financial support from national budget of the Technology Agency of the Czech Republic.

\section{References}

Altair HyperWorks [online]. 2012 [cited 01 October 2014]. Available from Internet: http://insider.altairhyperworks. com/intuitive-technology-foraec/

Čtverák, J.; Mertl, V.; Píštěk, A. 1997. Soubor podkladů pro pevnostní výpočty leteckých konstrukcí. Brno University of Technology, Brno.

EASA. 2012. CS-23 regulation - Certification Specifications for Normal, Utility, Aerobatic, and Commuter category aeroplanes. Amendment 3, EASA, 2012.

Jurek, P. 2013. Wing structure weight optimization of the aircraft L 410 NG: diploma thesis, Brno University of Technology, Brno. 
Katrňák, T.; Juračka, J. 2015. Detailed topometry FEM optimization of wing structural panel, Applied Mechanics and Materials 821: 357-363. https://doi.org/10.4028/www.scientific.net/AMM.821.357

Li, Z. K.; Bian, H. M.; Shi, L. J.; Niu, X. T. 2014. Reliabilitybased topology optimization of compliant mechanisms with geometrically nonlinearity, Applied Mechanics and Materials 556-562: 4422-4434. https://doi.org/10.4028/ www.scientific.net/AMM.556-562.4422

MacNeal-Schwedler Corporation. 1992. MSC NASTRAN handbook for non-linear analysis, Version 67. The MacNealSchwedler Corporation, Los Angeles, CA.
MacNeal-Schwedler Corporation. 2008. MSC NASTRAN Quick reference guide, Version 2008. The MacNeal-Schwedler Corporation, Los Angeles, CA.

Megson, T. H. G. 2007. Aircraft structures for Engineering students. 4th ed. Oxford: Elsevier. 824 p.

Niu, M. C. Y. 1999: Airframe stress analysis and sizing. 2nd ed. Hong Kong Conmilid Press Ltd. 795 p.

Qiu, G. Y. A.; Hu, P. A.; Zhou, W. B. 2014. Two-dimensional structural topology optimization based on isogeometric analysis, Applied Mechanics and Materials 472: 475-479. https://doi.org/10.4028/www.scientific.net/AMM.472.475 